\title{
Breastfeeding Practices and Dietary Diversity among Infants and Young Children in Rural and Urban-Slum Populations in India: An Observational Study
}

\author{
Urmila Deshmukh ${ }^{1, *}$, Tinku Thomas $^{2}$, Sumathi Swaminathan ${ }^{3}$ and Anura Kurpad ${ }^{4}$ \\ ${ }^{1}$ BioTRaK Research Foundation, Jatharpeth Road, Akola, Maharashtra, 444005, India \\ ${ }^{2}$ Department of Biostatistics, St. John's Medical College, Bangalore, Karnataka 560034, India \\ ${ }^{3}$ Division of Nutrition. St John's Research Institute, Bangalore, Karnataka 560034, India \\ ${ }^{4}$ Department of Physiology and Nutrition, St. John's Medical College, Bangalore, Karnataka 560034, India
}

\begin{abstract}
Background: Nutritional exposures and growth in early life are linked to immediate and also to long term health outcomes.

Objective: To assess infant and young child feeding (IYCF) practices using WHO-UNICEF defined indicators in rural and urban-slum populations in India.

Methods: A community-based, cross-sectional study was conducted in mothers and infants up to age 24 months. Data on socio-demographics, birth history, feeding practices (WHO-UNICEF IYCF indicators), maternal weight, height, and infant's weight, length, mid-arm, and head circumferences were collected.

Results: Five hundred and two (252 rural and 250 urban-slum) mother-infant dyads were studied. Proportions of IYCF indicators in rural and urban-slum infants were: Early initiation of breastfeeding 71 and $64 \%$; Exclusive breastfeeding under six months, 59 and 25\%; Minimum acceptable diet 11 and $27 \%$ respectively. Consumption of animal-source food (other than dairy products) and vitamin-A rich fruits and vegetables was below 15\%. Cesarean section [aOR, 95\% Cl: $2.94(1.53,5.65)]$, hospitalization of newborn [aOR, 95\% Cl: $6.21(2.95,13.16)]$, pre-lacteal feeding [aOR, $95 \% \mathrm{Cl}: 3.38$ $(1.77,6.45)$ ], needing help in breastfeeding [aOR, 95\% Cl: $2.15(1.04,4.17)$ ], and male gender [aOR, 95\% Cl: 2.13 $(1.15,4.25) ; p<0.05$ for all] were associated with delayed initiation of breastfeeding, whereas lower monthly household income [aOR, 95\% Cl: $2.62(1.10,6.25)]$, and younger age [aOR, 95\% Cl: $1.24(1.11,1.38) ; \mathrm{p}<0.05$ for both] were associated with poor dietary diversity.
\end{abstract}

Conclusions: Education of optimum IYCF practices, targeting early initiation of breastfeeding, increasing meal frequency and intake of vitamin-A rich and animal-source foods need urgent attention.

Keywords: Breastfeeding, complementary feeding, India, IYCF practices, predictors.

\section{INTRODUCTION}

Adequate provision of nutrients, beginning in early stages of life, is crucial to ensure good physical and mental development and long-term health. Despite the progress under the Millennium Development Goals, undernutrition and stunting are still the challenges faced by the low and middle-income countries (LMIC) including India [1]. In 2014, 50 million children under age 5 suffered from moderate or severe wasting, and more than two thirds of these lived in Asia [2]. Comparison of child growth patterns in 54 countries, including India, using WHO growth standards has shown growth faltering in weight and length in first two years of life [3].

Infant and young child feeding (IYCF) practices are important determinants of macro- and micronutrient intake in early life. In 2008, the WHO published a set of breastfeeding and complementary feeding indicators

*Address correspondence to this author at the BioTRaK Research Foundation, Jatharpeth Road, Akola, Maharashtra, 444005; India; Tel: +91 9823146829; Fax: +91 724 2420853; E-mail: deshmukh.urmila@gmail.com that could be used to assess infant feeding within and across countries [4, 5]. In India, secondary analyses of the National Family Health Survey data, and the Comprehensive Nutrition Survey in Maharashtra showed that IYCF practices are sub-optimal [6-9], and there is a need to study in-depth IYCF practices and its determinants in different locations and socio-economic strata. Mother-child nutrition has also been recently considered as an area of highest concern by the National Steering Group for setting research priorities in nutrition in India [10]. We have undertaken investigations, including determinants of child feeding practices, quantification of breast milk, and study of human milk macronutrient composition. This paper is first in the series, describing findings of IYCF practices from a cross-sectional survey.

\section{MATERIALS AND METHODS}

\section{Study Design, Setting and Participants}

A community based cross sectional study was conducted from April 2013 to March 2014 in rural part 
of Akola district in Maharashtra, and in urban-slum settlement of Bangalore city of Karnataka, in India. The rural population was from the nearest Health Subcentre from Akola city. Children up to the age of 2 years, from the community centers (Anganwadi) run by the Integrated Child Development Services (ICDS) scheme, were listed and their mothers were invited to participate in the study. In the urban area, a large notified urban slum settlement near the St. John's Research Institute was selected, and children under the age of two years were identified by door to door survey. The rural cohort represented population migrated from surrounding, more remote areas near a town area. The urban cohort was from slum area representing population migrated in a metro city for livelihood. Informed written consent was taken from the mothers. Permission was obtained from the local health authorities. The study was approved by the Ethics Committee of St John's Research Institute, Bangalore.

Based on previous observation of $20 \%$ prevalence of exclusive breast feeding in the Bangalore population [11], a sample size of 384 was deemed to be sufficient to observe the prevalence of exclusive breastfeeding, with $20 \%$ relative precision and $95 \%$ confidence interval. We planned to study 500 children, 400 infants up to 12 months age and 100 children between 12 and 24 months of age from both study sites.

\section{Data Collection}

Data on socio-demography, birth history, and feeding practices were obtained by an intervieweradministered questionnaire that was divided in to five sections: 1. General questionnaire, 2. Standard-ofliving questionnaire, 3. Birth history and initiation of breast feeding, 4 . Feeding practices and 5 . Morbidity in past four weeks of the interview. Feeding practices questionnaire was adapted from the WHO 2010 module of measurement of IYCF indicators [5]. A 24hour diet recall of the infant was also obtained on three days within a week's period (data not presented in this paper). Birth weight was recorded as recalled by mother and/ or confirmed from the birth records (Nursing Home Discharge Summary or Anganwadi register).

The weight of the mother was measured to the nearest $100 \mathrm{~g}$ using Tanita 325 Scale (Tanita, Japan), and height to the nearest $0.1 \mathrm{~cm}$ using CMS weighing equipment (London, U.K). Child's weight was measured on a calibrated electronic scale (Salter, Tonbridge, England) to the nearest $10 \mathrm{~g}$, and length, nearest to $0.1 \mathrm{~cm}$ using infantometer (Seca, Hammer Steindamm, Hamburg, Germany); head and mid arm circumferences were measured to the nearest $0.1 \mathrm{~cm}$ using Rollfix non-stretchable tape (Hoechstmass, Germany). The IYCF indicators were determined using the WHO-UNICEF definitions [4, 5]. Early initiation of breastfeeding was based on historic recall by mothers as infants who were put to the breast within $1 \mathrm{~h}$ of birth All other indicators are based on recall of practices from the previous day. For example, exclusive breastfeeding among infants $0-5$ months of age and continued breastfeeding at 1 year in 12-15 months old are calculated from recall of exclusive and any breastfeeding, respectively, on the previous day only.

\section{Statistical Methods}

Continuous data is reported as means and standard deviations (sd). Infant feeding practices are expressed as frequencies and percentages. Standard of living index (SLI) was determined as used in the National Family Health Survey of India, as a summary of household measures composed of 27 items, including consumer durables, agricultural machinery, housing conditions and access to water, light, fuel etc. with weightage varying from 0 through 4 . The index is calculated by summing the weights with possible scores ranging from 0 to 67 [7].

Child's nutritional status was measured using the WHO international growth standards [13], and z scores were derived from the WHO Anthro software (version 3.2.2, January 2011). Children who were 2 SD below the median for weight-for-height (WHZ), weight-for-age (WAZ) and height-for-age (HAZ) $z$ scores were classified as wasted, underweight and stunted respectively.

Based on the different socio-demographic, motherchild factors associated with IYCF in the literature, we first examined the individual association of factors (potential predictor variables such as SLI, monthly income, parental education, maternal employment before pregnancy, type and place of delivery, low birthweight, birth order and gender of child, maternal $\mathrm{BMI}$, number of children in household, hospitalization after birth, help with breastfeeding initiation, giving prelacteal feeds) with IYCF indicators by chi-square tests, using a cut-off of $P<0.05$ for each study site. Next, multiple logistic regression analysis was performed to assess the risk factors identified in bivariate analyses. The variables which retained statistical significance in the final model only are presented in the tables. The 
findings are presented as odds ratio (adjusted odds ratio, aOR) with $95 \%$ confidence intervals $(95 \% \mathrm{Cl})$. Data analysis was done using SPSS (IBM Corp. Released 2012. IBM SPSS Statistics for Windows, Version 21.0. Armonk, NY: IBM Corp).

\section{RESULTS}

Data were collected from 502 mother-child dyads: 250 urban-slum and 252 rural, of which 486 children belonged to age group 0 to 23 months, and were included in the analyses of feeding practices.

\section{Socio-Demographic and Mother-Child Charac- teristics}

Some of the socio-demographic characteristics, and mother-child body size are described in Table 1. The mean (sd) age of mothers from both sites was 24.6 (3.8) years, and $49 \%$ had only one living child. Majority of the study population lived as a joint family, and $75 \%$ of the households had one or two children. Four percent of rural and one percent of urban-slum mothers delivered at home, 57 and $79 \%$ delivered in government facility, respectively. The proportion of cesarean deliveries was $33 \%$ in rural and $20 \%$ in

Table 1: Socio-Demographic and Body Size Characteristics of the Study Population

\begin{tabular}{|c|c|c|}
\hline Variable & $\begin{array}{c}\text { Rural } \\
(n=252)\end{array}$ & $\begin{array}{l}\text { Urban-slum } \\
\qquad(n=250)\end{array}$ \\
\hline \multicolumn{3}{|l|}{ Type of Family, n (\%) } \\
\hline Nuclear & $55(22)$ & $117(47)$ \\
\hline Extended & $30(12)$ & $8(3)$ \\
\hline Joint & $167(66)$ & $125(50)$ \\
\hline \multicolumn{3}{|l|}{ Number of living children the mother has, $\mathbf{n}(\%)$} \\
\hline One & $123(49)$ & $121(48)$ \\
\hline Two & $103(41)$ & $84(34)$ \\
\hline Three or more & $26(10)$ & $45(13)$ \\
\hline \multicolumn{3}{|l|}{ Total number of children in households, $\mathbf{n}(\%)$} \\
\hline One & $92(36)$ & $104(42)$ \\
\hline Two & $96(38)$ & $89(36)$ \\
\hline Three or more & $45(26)$ & $57(22)$ \\
\hline \multicolumn{3}{|l|}{ Mother's Education (years of schooling), n (\%) } \\
\hline No education & $7(3)$ & $22(9)$ \\
\hline $1-8 y$ & $31(13)$ & $99(39)$ \\
\hline $9-13 y$ & $176(70)$ & $121(49)$ \\
\hline University & $38(15)$ & $8(3)$ \\
\hline \multicolumn{3}{|l|}{ Father's Education (years of schooling), $\mathrm{n}(\%)$} \\
\hline No education & $7(3)$ & $35(14)$ \\
\hline $1-8 y$ & $42(16)$ & $94(37)$ \\
\hline $9-13 y$ & $160(63)$ & $116(46)$ \\
\hline University & $43(17)$ & $5(2)$ \\
\hline Standard of Living score, mean (sd) & $29(9)$ & $25(6)$ \\
\hline Mothers' BMI $\left(\mathrm{kg} / \mathrm{m}^{2}\right)$, mean (sd) & $20.9(3.1)$ & $22.3(4.1)$ \\
\hline Child characteristics, mean (sd) & $(n=249)$ & $(n=237)$ \\
\hline Age (mo) & $6.8(6.3)$ & $7.8(6.9)$ \\
\hline Male (n, \%) & $125(50)$ & $120(48)$ \\
\hline Infants below 6 mo age $(n)$ & 155 & 128 \\
\hline Length for age $z$ score, HAZ & $-1.03(1.4)$ & $-1.0(1.3)$ \\
\hline Weight for age $z$ score, WAZ & $-1.43(1.1)$ & $-1.06(1.0)$ \\
\hline Weight for length z score, $\mathrm{WHZ}$ & $-1.03(1.0)$ & $-0.6(1.4)$ \\
\hline
\end{tabular}


urban-slum sample. Twenty-four percent of rural mothers were underweight $\left(\mathrm{BMl}<18.5 \mathrm{~kg} / \mathrm{m}^{2}\right)$ and $19 \%$ of urban-slum mothers were overweight (BMI $>25$ $\left.\mathrm{kg} / \mathrm{m}^{2}\right)$. The mean birth weight of infants was $2.7(0.5)$ $\mathrm{kg}$ in rural and $2.8(0.6) \mathrm{kg}$ in urban-slum sample, and $19 \%$ were born low birth weight $(<2.5 \mathrm{~kg})$. Compared to the WHO Growth Standards, mean anthropometric $\mathrm{z}$ scores were below the median, and the proportion of wasting, underweight and stunting was $16 \%, 29 \%$ and $25 \%$ in rural and $16 \%, 19 \%$ and $21 \%$ in urban-slum children respectively. The median monthly household earning was 7500 rupees in rural and 8000 rupees in urban-slum households.

\section{Breastfeeding Practices}

Indicators of breastfeeding and complementary feeding practices are described in Table 2. Early initiation of breastfeeding was seen in $71 \%$ rural and $64 \%$ of urban-slum children, but exclusive breastfeeding for first six months was reported in only $59 \%$ rural and $25 \%$ of urban-slum children. Seventyseven percent of rural and $46 \%$ of urban-slum mothers received advice about starting breastfeeding after delivery; $65 \%$ of rural mothers were advised by the doctor, and $50 \%$ of urban-slum mothers by the child's grandmother. About $6 \%$ of rural and $11 \%$ of urban-slum mothers reported having had some difficulty in the initiating breastfeeding. In the first 3 days of life $37 \%$ of the rural and $49 \%$ of the urban-slum children received pre-lacteal feeds, and within them $60 \%$ were offered it only once or twice. In $46 \%$ of those rural infants prelacteal feed consisted of milk other than the breast milk, and in urban-slum it was sugar or jaggery water. All, except one urban-slum child, were reported to be 'ever breastfed'. The average frequency of breast feeding in all infants below the age of six months was 7 times during the day and 3 times during the night. Continued breastfeeding at or beyond 12 months was reported by $90 \%$ rural and $87 \%$ of urban-slum mothers.

\section{Complementary Feeding Practices in 6 to 23 Months Old Children}

The mean (sd) age of starting complementary feeds was 6.8 (1.9) in rural and 5.5 (2.0) months in urbanslum infants, and in $71 \%$ of rural and $79 \%$ of urbanslum infants complementary feeding was started in 6 to 8 months of age. Thirteen percent rural and $21 \%$ urban-slum children in age group 6 to 23 months were not breastfed in last 24 hours, and the mean (sd) frequency of complementary feeding was 4.3 (1.9) and 2.6 (0.9) times per day, respectively. The mean (sd) age of stopping breastfeeding was 14.8 (4.8) months. About $50 \%$ mothers said that they planned to continue breastfeeding till the infant is 24 months old.

Table 2: Breastfeeding and Complementary Feeding Practices (Proportions) in Children

\begin{tabular}{|c|c|c|}
\hline Breastfeeding Indicators & Rural & Urban-slum \\
\hline \hline Ever breastfed & 100 & 71 \\
\hline Early initiation of breastfeeding & 59.4 & 99.6 \\
\hline Exclusive breastfeeding under 6 mo & 90 & 25 \\
\hline Continued breastfeeding at 1 year & 63 & 87 \\
\hline Age-appropriate breastfeeding & 36 & 44.3 \\
\hline Predominant breastfeeding under 6 mo & 2.4 & 58.6 \\
\hline Bottle-feeding under 6 mo & \multicolumn{2}{|c|}{71.4} \\
\hline Complementary Feeding Indicators & $4.3(1.9)$ & 10.9 \\
\hline Introduction of solid, semi-solid or soft foods & $3.0(1.2)$ & $2.6(0.9)$ \\
\hline Frequency of complementary feeds per day, mean (sd) & 90.4 & $3.3(1.4)$ \\
\hline Food groups score, mean (sd) & 13.8 & 10.6 \\
\hline Minimum meal frequency & 41.8 \\
\hline Minimum dietary diversity & 46.8 \\
\hline Minimum acceptable diet & 26.6 \\
\hline
\end{tabular}

All numbers indicate percentages, unless specified. [Minimum meal frequency: For breastfed children: $6-8$ months of age: 2 times/d; $9-23$ months of age: 3 times/d for non-breastfed: 4 times/d. Minimum acceptable diet: Breastfed children (6-23 mo) who had at least the minimum dietary diversity and the minimum meal frequency during the previous day; non-breastfed children who received at least 2 milk feedings and had at least the minimum dietary diversity not including milk feeds, and the minimum meal frequency during the previous day]. 


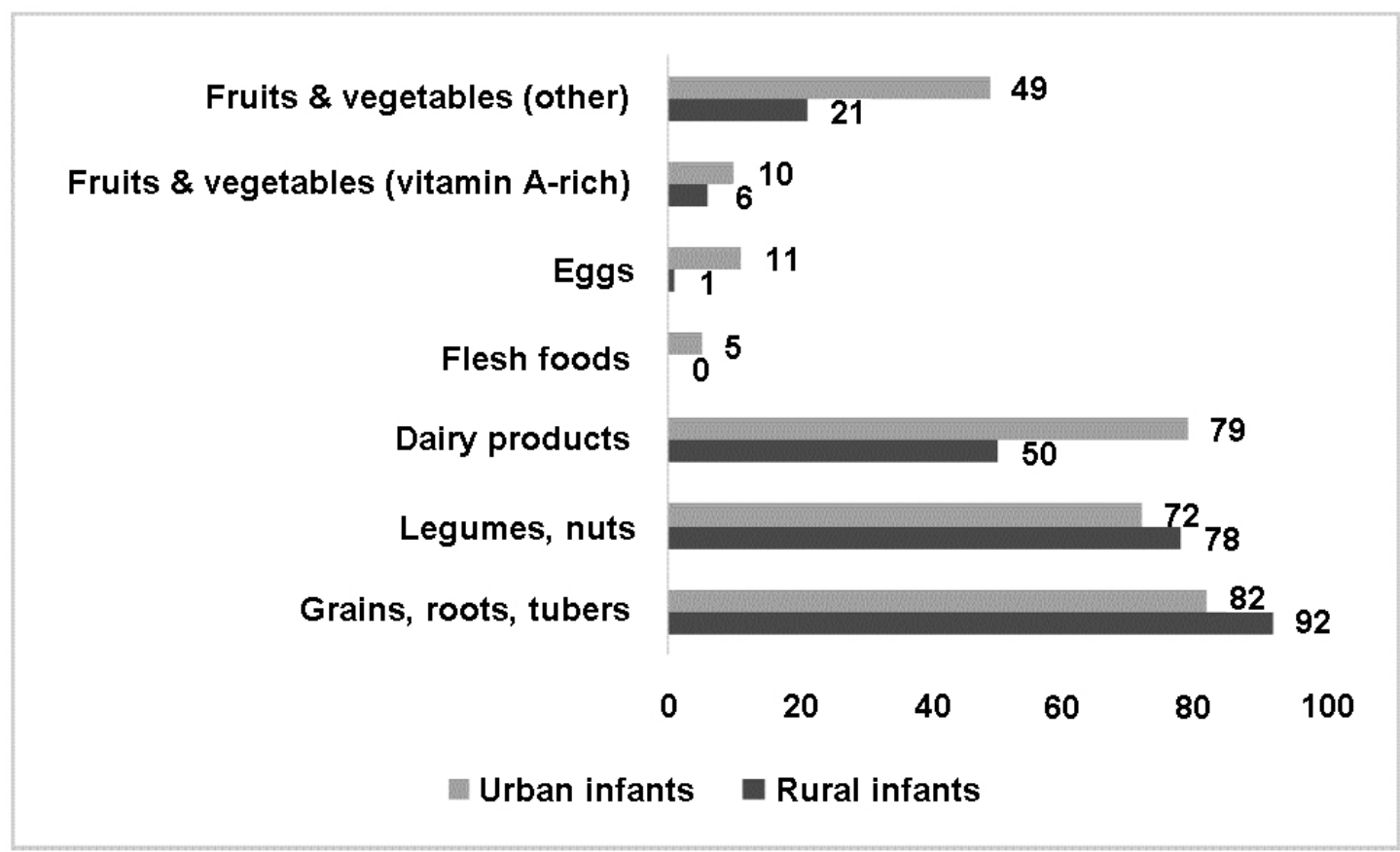

Figure 1: Consumption of food items from seven food groups in urban-slum and rural children aged 6 to 23 months.

Commercial infant food was used by $20 \%$ of rural and $26 \%$ of urban-slum mothers.

In rural infants, the mean frequency of consumption of semi-solid or soft food was 4.3 (1.9) per day, frequency of breastfeeding 8 (3.7) times per day, and the mean food group score was 3 (1.2) per day. In urban-slum sample, mean feeding frequency was 2.6 (0.9) per day, food group score was 3.3 (1.4) (Table 2). Figure 1 shows the proportion of food consumed from seven defined food groups in rural and urban-slum children. The frequency of dairy item (79 vs. $50 \%$ ) and non-vegetarian food (16 vs. $1 \%$ ) consumption was higher in urban-slum than in rural infants respectively. Seventy percent of rural and $63 \%$ urban-slum mothers said they were told about weaning, by a relative or a health worker. Rural mothers said that they usually get advice about what the child should be fed, from a local doctor $(30 \%)$ or from a community health worker $(26 \%)$ or mother-in-law (17\%), and $20 \%$ utilize their own experience from previous child; urban-slum mothers decided on their own $(37 \%)$ or were advised by motherin-law $(24 \%)$, neighbor $(15 \%)$ or doctor $(11 \%)$. Overall, the rural children had poor dietary diversity $(14 \%)$ and acceptable diet was seen in only $11 \%$ children. Thirtyseven percent of the rural infants and $50 \%$ of the urban-slum infants were taken to a local doctor for some or the other illness in previous four weeks of interview; in majority the reason was acute respiratory illnesses.

\section{Associations of Socio-Demographic, Mother-Child Factors and Feeding Practices}

Breastfeeding (exclusive or predominant) under six months was seen in about $85 \%$ of the study infants. There was no association of exclusive breastfeeding under six months with any of the demographic variables measured, including family type, SLI, parental education, place and mode of delivery, birth order or with child's anthropometric $z$ scores (data not shown).

In rural children, failure of early initiation of breastfeeding was associated directly with cesarean delivery, mothers who required help in initiating breastfeeding, offering pre-lacteal feeds, male offspring, and hospitalization of offspring to neonatal care unit, and in urban-slum sample, with delivery in private nursing home. After adjusting for various sociodemographic and maternal-infant factors, failure to initiate breastfeeding within an hour of delivery was almost three times more common in caesarean delivery in both rural and urban-slum sample; thrice in rural children who received pre-lacteal feeds, twice in males and in those where the mother required help in initiating breastfeeding (Table 3). Rural children who required hospitalization in perinatal period were at the highest risk of delayed initiation of breastfeeding.

In both rural and urban-slum children, food group score was directly associated with child's age $(r=0.26$, $P=0.011$ and $r=0.56, P<0.001$ ) and frequency of feeds 
Table 3: Characteristics Associated with Failure of Early Initiation of Breastfeeding in Rural and Urban-Slum Infants and Young Children

\begin{tabular}{|c|c|c|}
\hline Characteristics & Rural sample & Urban-slum sample \\
\cline { 2 - 3 } & aOR (95\% Cl) & aOR (95\% CI) \\
\hline \hline Delivery by caesarean section & $2.94(1.53,5.65)^{\star * *}$ & $2.65(1.38,5.10)^{\star *}$ \\
\hline Hospitalisation in neonatal period & $6.21(2.95,13.16)^{\star * *}$ & - \\
\hline Pre-lacteal feeds given & $3.38(1.77,6.45)^{\star * *}$ & - \\
\hline Received help in breastfeeding in nursing home & $2.15(1.04,4.17)^{\star}$ & - \\
\hline Offspring gender, Male & $2.13(1.15,4.25)^{*}$ & - \\
\hline
\end{tabular}

aOR, adjusted odds ratio (Adjusted for all variables statistically significant in the bivariate analysis). ${ }^{*} P<0.05,{ }^{* \star} P<0.01,{ }^{* \star *} P<0.001$.

per day $(\mathrm{r}=0.51, \quad P<0.001$ and $\mathrm{r}=0.27, \quad P=0.005$, respectively). In rural sample, risk of poor dietary diversity (food groups <4) was four times more in children of mothers with formal education less than 9 years, compared to those whose mothers had education 9 or more years [OR, 95\% Cl: 4.27 (1.21, 15.06), $P=0.03$ ]; and was eight times more in households in lowest tertile of income [OR, $95 \% \mathrm{Cl}$ : 7.79 (1.50, 40.37), $P=0.012$ ] than in the highest income tertile. In adjusted analysis, only monthly household income was associated with dietary diversity [aOR, $95 \% \mathrm{Cl}: 2.62$ (1.10, 6.25), $P=0.030]$. In urban-slum sample, dietary diversity was positively associated with child's age, and no breastfeeding in last $24 \mathrm{~h}$; and adjusted analysis showed that older children were more likely to get more diverse diet than younger infants [aOR, 95\% Cl: $1.24(1.11,1.38), P<0.001]$.

\section{DISCUSSION}

In this survey we have studied child feeding practices in rural and urban-slum populations, in two states of India using similar methodology. Comparative evaluation of IYCF practices in Indian children, using WHO-UNICEF indicator definitions, from large data sets is shown in Table 4 [7, 12, 14]. Breastfeeding indicators show an improving trend of early initiation and exclusive breastfeeding practices, but the gain is not very appreciable. Similar observation is noted in the comparative analyses of exclusive breastfeeding practices in India's national data of year 1992-93 and 2005-06, which was carried out to guide policy makers in the development of targeted breastfeeding promotion strategies [15].

The predictors of delayed initiation of breastfeeding viz. delivery by caesarean section, hospitalization of neonate, giving pre-lacteal feeds, mothers who require support in breastfeeding, and male gender are consistent with those observed in other reports $[16,17]$. The proportion of institutional deliveries in India is rising, and rates of caesarean section are doubled, from $8.5 \%$ in NFHS-3 to $17.2 \%$ in NFHS-4 [7]. This underpins the need to enhance facility-based IYCF training to the healthcare staff. Male infants were less likely to receive early breastfeeding, which is also described in the African and Latin American sites of the multi-country IYCF study, the reason of which is not clear and speculated to be cultural [16]. We did not find gender preference in any other feeding practices.

Table 4: Prevalence of Infant and Young Child Feeding Indicators Published in Selected Studies from India.

\begin{tabular}{|c|c|c|c|c|c|}
\hline Indicators of infant feeding & \multicolumn{2}{|c|}{$\begin{array}{c}\text { Present Study } \\
\text { Rural Urban-slum }\end{array}$} & $\begin{array}{c}\text { NFHS-3 } \\
\text { (2005-06) [12] }\end{array}$ & $\begin{array}{c}\text { Mumbai Study } \\
\text { (2013) [14] }\end{array}$ & (2015-16) [7] \\
\hline \hline Early initiation of breastfeeding & 71 & 64 & 23.4 & 46 & 41.6 \\
\hline Exclusive breastfeeding under 6 mo & 59.4 & 25 & 46.4 & 62.6 & 73.5 \\
\hline Continued breastfeeding at 1y & 90 & 87 & 85 & 41.2 & 42.9 \\
\hline Introduction of semi-solid or soft foods & 71.4 & 78.8 & 64 & 43.3 & na \\
\hline Minimum meal frequency & 90.4 & 41.8 & 45 & 13 & na \\
\hline Minimum dietary diversity & 13.8 & 46.8 & 9 & 4.7 & 9.6 \\
\hline Minimum acceptable diet & 10.6 & 26.6 & 9 & & 4.7 \\
\hline
\end{tabular}

na= data not available. 
Traditional practice of offering pre-lacteal feeds like honey, sugar or jaggery water, still widely prevalent, needs to be discouraged. Low rates of 'exclusive' breastfeeding under six months, but high proportion of 'ever breastfed' infants (99\%) and continued breastfeeding at one year (88\%) in our study indicate that breastfeeding is a cultural norm in this population, but 'exclusivity' of breastfeeding under the age of six months needs to be targeted. Recent review and metaanalyses have shown that delayed initiation of breastfeeding ( $\geq 24$ hours after birth) had an $85 \%$ (95\% Cl: $29-167 \%)$ greater risk of neonatal mortality compared to infants in whom it is initiated early $(<24$ hours after birth) [17]. It is estimated that scaling up of breastfeeding can prevent 823,000 child deaths every year all over, and might contribute to achievement of the Sustainable Development Goals [18]. In terms of morbidity reduction, about half of all diarrhoea episodes, a third of respiratory infections and $68 \%$ of malocclusions would be avoided by breastfeeding [18].

The proportion of children who received 'age appropriate breastfeeding' was low in our study, as this indicator is composite of proportion of exclusive breastfeeding and introduction of semi-solid food. Delayed introduction of semi-solid food, and persistent breastfeeding when breast milk may not fulfil the energy requirements of a growing infant may lead to undernutrition and micronutrient deficiencies.

Complementary feeding practices observed in our study and in other larger data sets need serious attention. Regional data of NFHS-4, from same places where we conducted our survey, show that only $16.1 \%$ of children in Bangalore (urban) region and none $(0 \%)$ from rural Akola received an adequate diet [7]. Dietary patterns established in early life are strongly influenced by socio-demographic and maternal factors and remain so over initial years. A recent longitudinal study of dietary pattern trajectories of infants in multi-ethnic Asian cohort reported that Indian mothers had a higher start scores on easy-to-prepare foods but greater adherence to 'predominant' breastmilk with time [19]. The analyses of national survey data of five South Asian countries - Bangladesh, India, Nepal, Pakistan and Sri Lanka, showed that poverty, low level of maternal education, lower frequency of antenatal visits and no exposure to media were the factors associated with inappropriate feeding practices [20]. Positive associations of food group score with infant's age and with frequency of meals in our survey indicate that efforts to educate the mother and other family members about these may help to increase dietary diversity and consequently micronutrient intake.

Our study has certain limitations. The sample size calculation did not take into account IYCF indicators other than prevalence of exclusive breastfeeding. We chose a convenient sample, and no special sampling technique was used, as we wanted to carry out a longitudinal study of quantification of breastmilk in the same sample. We did not measure water, sanitation and hygiene (WASH) practices, which are also shown to be important determinants of child health and nutrition in India [21].

The findings of poor rates of some of the IYCF indicators and relatively better rates of other in our study could be explained by a mix of socio-cultural practices such as universal and prolonged breastfeeding on one hand, and offering ritual fluids in addition to breast milk on the other. Inequalities in child health, including breastfeeding practices within population groups (rural vs. urban), and between Indian states are well described, and are ascribed to lack of universal health education and healthcare access [22].

In conclusion, our study highlights need of interventions that seek to increase proportion of early initiation of breastfeeding or feeding own mother's milk, in situations such as cesarean delivery, and in high risk newborns, and to discourage pre-lacteal feeding. Similarly, effective interventions should be designed to increase dietary diversity in children beyond age of six months, as this age is considered as a nutritionally turbulent time for an infant that may influence later health and development [23]. This would help to address child undernutrition in India.

\section{CONCLUSION}

Our study highlights suboptimal rates of exclusive breastfeeding under 6 months, and largely inadequate complementary feeding after 6 months of age. Interventions that seek to increase early initiation of breastfeeding should be focused more on situations such as operative delivery and high risk newborns who need special care support. Recent focus on potential pathways and mechanisms through which infant feeding may influence non-communicable disease risk in later life, suggest a need to investigate in detail nutrients provided from human milk and from homemade complementary foods. This will also help to design interventions to prevent undernutrition in under5 children in India. The WHO indicators are valuable 
tools for broadly assessing the quality of infant diets and for monitoring population trends in IYCF practices over time.

\section{ACKNOWLEDGEMENT}

We thank Ms Swati, Ms Shaheena, Ms Jayashree and Ms Sapna who helped in data collection. We also thank the participants, and community health workers in the study area.

\section{FUNDING}

We thank the International Atomic Energy Agency (IAEA), Vienna, Austria for funding this study. This study is part of a doctoral, co-ordinated research project funded by the IAEA, titled 'Stable isotope techniques to assess intake of human milk and body composition of infants and young children up to 2 years of age'.

\section{CONFLICTS OF INTEREST}

The authors declare that they have no competing interests.

\section{REFERENCES}

[1] Richter LM, Daelmans B, Lombardi J, Heymann J, Boo FL, Behrman JR, et al. Paper 3 Working Group and the Lancet Early Childhood Development Series Steering Committee. Investing in the foundation of sustainable development: pathways to scale up for early childhood development. Lancet 2017; 389: 103-118.

https://doi.org/10.1016/S0140-6736(16)31698-1

[2] For every child, a fair chance. UNICEF Report; 2015. ISBN: 978-92-806-4817-1 [cited 14th August 2018]: Available from: https://www.unicef.org/publications/files/For_every_child_a_f air_chance.pdf

[3] Victora CG, de Onis M, Hallal PC, Blössner M, Shrimpton R. Worldwide timing of growth faltering: revisiting implications for interventions. Pediatrics 2010; 125: e473-80. https://doi.org/10.1542/peds.2009-1519

WH, IFPRI, UC Davis, FANTA, USAID, UNICEF, Indicators for assessing infant and young child feeding practices: Part 1 - Definitions, Geneva, World Health Organization, 2008 [cited 14 August 2018]: http://apps.who.int/iris/bitstream/10665/ 43895/1/9789241596664_eng.pdf

WHO, IFPRI, UC Davis, FANTA, USAID, UNICEF, Indicators for assessing infant and young child feeding practices: Part 2 - Measurement, Geneva, World Health Organization, 2010 [cited 14 August 2018]: http://apps.who.int/iris/bitstream/ 10665/44368/1/9789241599757_eng.pdf

[6] Patel A, Pusdekar Y, Badhoniya N, Borkar J, Agho KE, Dibley MJ. Determinants of inappropriate complementary feeding practices in young children in India: secondary analysis of National Family Health Survey 2005-2006. Matern Child Nutr 2012; 8(Suppl 1): 28-44. https://doi.org/10.1111/j.1740-8709.2011.00385.x

[7] International Institute for Population Sciences. National Family Health Survey (NFHS-4), 2015-16, India Fact Sheet [cited 14 August 2018]: http://rchiips.org/NFHS/pdf/NFHS4/ India.pdf
Menon P, Bamezai A, Subandoro A, Ayoya MA, Aguayo V. Age-appropriate infant and young child feeding practices are associated with child nutrition in India: insights from nationally representative data. Matern Child Nutr 2015; 11: 73-87.

https://doi.org/10.1111/mcn.12036

Aguayo VM, Nair R, Badgaiyan N, Krishna V. Determinants of stunting and poor linear growth in children under 2 years of age in India: an in-depth analysis of Maharashtra's comprehensive nutrition survey. Matern Child Nutr 2016; 12(Suppl 1): 121-40. https://doi.org/10.1111/mcn.12259

[10] Arora NK, Mohapatra A, Gopalan HS, Wazny K, Thavaraj V Rasaily $\mathrm{R}$, et al. Setting research priorities for maternal, newborn, child health and nutrition in India by engaging experts from 256 indigenous institutions contributing over 4000 research ideas: a CHNRI exercise by ICMR and INCLEN. J Glob Health 2017; 7: 011003. https://doi.org/10.7189/jogh.07.011003

[11] Samuel TM, Thomas T, Bhat S, Kurpad AV. Are infants born in baby-friendly hospitals being exclusively breastfed until 6 months of age? Eur J Clin Nutr 2012; 66: 459-65. https://doi.org/10.1038/ejcn.2011.179

[12] IIPS and Macro International. 2008. National Family Health Survey (NFHS-3), India, 2005-06: Maharashtra. International Institute for Population Sciences and Macro International, Mumbai.

[13] WHO Multicentre Growth Reference Study Group. WHO Child Growth Standards based on length/height, weight and age. Acta Paediatr Suppl 2006; 450: 76-85.

[14] Bentley A, Das S, Alcock G, Shah More N, Pantvaidya S, Osrin D. Malnutrition and infant and young child feeding in informal settlements in Mumbai, India: findings from a census. Food Sci Nutr 2015; 3: 257-71.

https://doi.org/10.1002/fsn3.214

[15] Chandhiok N, Singh KhJ, Sahu D, Singh L, Pandey A. Changes in exclusive breastfeeding practices and its determinants in India, 1992-2006: analysis of national survey data. Int Breastfeed J 2015; 10: 34.

https://doi.org/10.1186/s13006-015-0059-0

[16] Patel A, Bucher S, Pusdekar Y, Esamai F, Krebs NF, Goudar SS, et al. Rates and determinants of early initiation of breastfeeding and exclusive breast feeding at 42 days postnatal in six low and middle-income countries: A prospective cohort study. Reprod Health 2015; 12(Suppl 2): S10.

https://doi.org/10.1186/1742-4755-12-S2-S10

[17] Smith ER, Hurt L, Chowdhury R, Sinha B, Fawzi W, Edmond KM. Neovita Study Group. Delayed breastfeeding initiation and infant survival: A systematic review and meta-analysis. PLoS One 2017; 12: e0180722.

[18] Victora CG, Bahl R, Barros AJ, França GV, Horton S, Krasevec J, Murch S, Sankar MJ, Walker N, Rollins NC Lancet Breastfeeding Series Group. Breastfeeding in the 21st century: epidemiology, mechanisms, and lifelong effect. Lancet 2016; 387: 475-90. https://doi.org/10.1016/S0140-6736(15)01024-7

[19] Lim GH, Toh JY, Aris IM, Chia AR, Han WM, Saw SM, Godfrey KM, Gluckman PD, Chong YS, Yap F, Lee YS, Kramer MS, Chong MF. Dietary Pattern Trajectories from 6 to 12 Months of Age in a Multi-Ethnic Asian Cohort. Nutrients 2016; 8(6): pii: E365

[20] Senarath U, Dibley MJ. Complementary feeding practices in South Asia: analyses of recent national survey data by the South Asia Infant Feeding Research Network. Matern Child Nutr 2012; 8(Suppl 1): 5-10. https://doi.org/10.1111/j.1740-8709.2011.00371.x

[21] Rah JH, Cronin AA, Badgaiyan B, Aguayo VM, Coates S, Ahmed S. Household sanitation and personal hygiene practices are associated with child stunting in rural India: a 
cross-sectional analysis of surveys. BMJ Open 2015; 5: e005180.

[22] Pappachan B, Choonara I. Inequalities in child health in India. BMJ Paediatrics Open 2017; 1: e000054.
[23] Kuriyan R, Kurpad AV. Complementary feeding patterns in India. Nutr Metab Cardiovasc Dis 2012; 22: 799-805. https://doi.org/10.1016/j.numecd.2012.03.012

Received on 17-09-2018

https://doi.org/10.6000/1929-4247.2018.07.04.7

(C) 2018 Deshmukh et al.; Licensee Lifescience Global.

This is an open access article licensed under the terms of the Creative Commons Attribution Non-Commercial License (http://creativecommons.org/licenses/by-nc/3.0/) which permits unrestricted, non-commercial use, distribution and reproduction in any medium, provided the work is properly cited. 